\title{
UN CUENTO CABALLERESCO DE DON JUAN MANUEL: EL EJEMPLO XXV DE EL CONDE 'LUCANOR
}

El carácter caballeresco del ejemplo XXV de El conde Lucanor ha sido detectado por varios críticos. Así, H. Tracy Sturcken señala que este cuento es cuasi-caballeresco y Reinaldo Ayerbe-Chaux apunta que tiene virtudes caballerescas ${ }^{1}$. Como nadie, sin embargo, ha explorado la cuestión, intentaré explicar dónde reside exactamente el carácter caballeresco de este ejemplo y cómo se inserta en la literatura caballeresca hispánica, por una parte, y en el pensamiento de don Juan Manuel, por otra.

El ejemplo XXV tiene cuatro personajes principales, que son: Saladino, su prisionero, el conde de Provenza, la hija única de éste, a quien pretenden hombres de alta alcurnia y considerable poder, y el hombre de menos linaje y riqueza, pero más virtudes, con el que su padre le ordena que se case siguiendo el consejo del sultán. Este hombre, después de celebrada la boda y antes de consumar el matrimonio, sale a probar su hombría, lo que hace rescatando a su suegro mediante una astuta y valiente operación en la que apresa a Saladino. El sultán, encantado con el acierto de su consejo, no sólo libera al conde de Provenza, sino que le da generosos regalos.

Cabe preguntarse cuál de estos elementos convierte al cuento en caballeresco a los ojos de los críticos. La aparición de Saladino, gran figura de la koiné caballeresca internacional, en expresión de Américo Castro, es una pincelada caballeresca, pero no convierte al cuento en caballeresco, como demuestra el hecho de que la aparición del sultán en el ejemplo L no haya tenido ese

${ }^{1}$ H. Tracy Sturcken, Don Juan Manuel, Twayne, New York, 1974, p. 83; Reinaldo AYerbe-ChauX, El conde Lucanor. Materia tradicional y originalidad creadora, José Porrúa Turanzas, Madrid, 1975, p. 130. 
efecto ${ }^{2}$. Lo que hace que el cuento sea caballeresco es la presencia de la estructura narrativa de los relatos folklóricos de pruebas matrimoniales, los cuales se caracterizan por presentar un héroe salvador que supera una prueba bélica y se casa con la princesa heredera. Normalmente hay también un rey viejo y un malvado agresor, que suelen morir muy oportunamente. También puede haber otros personajes, como auxiliares, donantes, etcétera.

Se trata de un tipo muy conocido de relato folklórico, el cual constituye la base de la mayoría de las novelas de caballerías hispánicas ${ }^{3}$. Aunque los críticos no han afirmado esto de una manera explícita, lo han dicho implícitamente. Por ejemplo, María Rosa Lida de Malkiel y Armando Durán notan que en las novelas de caballerías hispánicas lo importante es la acción externa, es decir, la lucha y el matrimonio, mientras que en las francesas lo que importa es la acción interna, es decir, la aventura y el amor ${ }^{4}$. Lo que ellos consideran una diferencia estilística es, en realidad, una diferencia estructural, ya que depende de los diversos tipos de relatos folklóricos que sirven de base a unas y a otras novelas. La mayoría de las novelas de caballerías hispánicas se basa en los relatos folklóricos de pruebas matrimoniales, mientras que la mayoría de las francesas se basa en los relatos folklóricos de tareas y búsquedas ${ }^{5}$. Por esto, cada vez que la estructura narrativa de los relatos folklóricos de pruebas matrimoniales aparece en obras que no son novelas o que no se consideran novelas de caballerías, los críticos, oyendo campanas, pero no sabiendo dónde, hablan de aires caballerescos. Éste es el caso, por ejemplo, de La Gran Conquista de Ultramar, crónica en la que se relata el matrimonio de Beatriz con el Caballero del Cisne, quien la defiende del ataque de Rayner de Saxoña, y de Otas, novela en la que se relata el matrimonio de Florencia con Esmeré, quien la libera del asedio de Garsir. Este aire caballeresco que los críticos perciben es mucho más que eso. Es la estructura narrativa de los p. 22.

2 Américo Castro, Semblanzas y estudios españoles, Ínsula, Madrid, 1956,

${ }^{3}$ Motivos H300-H499 de la clasificación de STith Thompson, Motif-index of folk-literature, ed. rev., Indiana University Press, Bloomington, IN 19551958,6 ts.

${ }^{4}$ MARía Rosa Lida de MAlKIel, Estudios de literatura española y comparada, EUDEBA, Buenos Aires, 1966, pp. 147-148; ARMANDo DURÁn, Estructura y técnicas de la novela sentimental y caballeresca, Gredos, Madrid, 1973.

${ }^{5}$ Motivos H900-H1399 de la clasificación de Stith Thompson. 
relatos folklóricos de pruebas matrimoniales, la cual apareció por primera vez en la literatura peninsular en las crónicas, extendiéndose luego a las novelas, a los cuentos y a otras obras ${ }^{6}$. Esta estructura narrativa está presente sólo en un ejemplo de El conde Lucanor: el XXV. Por esto, aunque en la obra haya ejemplos como el XXXV, en que un héroe (el mancebo) se casa con una heredera (la mujer brava) y supera una prueba (domarla), y ejemplos como el XV, en que un héroe (Lorenzo Suárez Gallinato) supera una prueba bélica (esperar el ataque de los moros sin moverse) como no juntan el matrimonio con la lucha, no han sido percibidos como caballerescos por los críticos.

El ejemplo XXV, en cambio, es un cuento caballeresco que puede y debe compararse con las novelas de caballerías hispánicas, con las que coincide plenamente. Así, el hombre es el héroe salvador y la hija del conde de Provenza es la princesa heredera. En cuanto al conde de Provenza, es el rey viejo. El único personaje que se sale un poco de lo común es Saladino, el malvado agresor, que no es malo, sino bueno. Sin embargo, dado el simbolismo de su figura, antes mencionado, esto no disminuye, sino que aumenta el carácter caballeresco del cuento, ya que le da más valor a la prueba bélica: vencer a un espejo de caballerías como Saladino tiene un mérito especial.

Se ha dicho que el ejemplo XXV se aparta considerablemente de las versiones precedentes, siendo, en realidad, una combinación de dos cuentos diferentes que no aparecen juntos con anterioridad: el del hombre bueno como mejor marido y el del pariente como liberador de un cautivo ${ }^{7}$. Esta combinación que produce un cuento netamente caballeresco no parece, sin embargo, casual, ya que se ajusta fielmente al modelo caballeresco en boga en tiempo de don Juan Manuel.

${ }^{6}$ Sobre el origen y desarrollo de la literatura caballeresca hispánica, véanse los siguientes estudios: HENRY ThOMAS, Spanish and Portuguese romances of chivalry, Cambridge University Press, Cambridge, 1920; José Amezcua, Metamorfosis del caballero. Sus transformaciones en los libros de caballerias españoles, Universidad Autonóma Metropolitana, México, 1984; Federico Francisco Curto Herrero, Estructura de los libros españoles de caballerías en el siglo XVI, Fundación Juan March, Madrid, 1976; DANIEl EISENBERG, Romances of chivalry in the Spanish Golden Age, Juan de la Cuesta Hispanic Monographs, Newark, DE, 1982; James D. Fogelquist, El "Amadís" y el género de la historia fingida, Porrúa Turanzas, Madrid, 1982; CRistina González, "El Cavallero Zifar" y el reino lejano, Gredos, Madrid, 1984.

7 Reinaldo Ayerbe-Chaux, op. cit., pp. 126-127. 
Efectivamente, en la literatura caballeresca hispánica pueden distinguirse tres fases. La primera fase comprende, aproximadamente, los siglos XII y XIII, que constituyen la época del feudalismo y del románico, periodo romántico y estático, en el cual, por una parte, la nobleza se establece firmemente y se hace hereditaria y conservadora y, por otra, no hay una clase media frente a la clase alta. Las obras caballerescas de esta época, en la que los reyes son fuertes, son principalmente crónicas latinas y castellanas. En las crónicas latinas - fundamentalmente la Historia Karoli Magni et Rotholandi, el Chronicon Mundi y De rebus Hispaniae - hay detalles caballerescos, sobre todo en la última, la cual presenta una versión breve, pero completa, de los relatos folklóricos de pruebas matrimoniales: las aventuras de Carlos Maynete y Galiana. En las crónicas castellanas, que son fundamentalmente la Estoria de España, la General Estoria y La Gran Conquista de Ultramar, hay episodios caballerescos, sobre todo en la última, la cual presenta tres versiones largas y elaboradas de los relatos folklóricos de pruebas matrimoniales: las aventuras del Caballero del Cisne y Beatriz, las aventuras de Gudufre de Bullon y la doncella y las aventuras de Carlos Maynete y Halia. La literatura caballeresca de esta fase, que se caracteriza por la defensa de la monarquía y de la continuidad social, presenta un héroe rico, un heredero que merece lo que tiene. Este tipo de caballero recibe dos herencias: la de su padre y la de su suegro. Esto se debe no sólo a los gustos del periodo, sino también a las exigencias del género: los protagonistas de las crónicas suelen ser reyes o emperadores, los cuales, por lo general, son príncipes herederos. A este periodo pertenece también el Amadís primitivo, que parece haberse compuesto a finales del siglo XIII.

La segunda fase abarca, más o menos, los siglos XIv y xv, que constituyen la época del capitalismo y del gótico, periodo realista y dinámico, en el cual, por una parte, la alta nobleza es sustituida por la baja nobleza, que es progresista y, por otra, aparece una clase media con acceso a la clase alta. Las obras caballerescas de esta época, en la que los reyes son débiles, son novelas de caballerías más o menos originales como el Zifar, el Otas, el Curial y el Tirant. La literatura caballeresca de esta fase, que se caracteriza por la defensa de la nobleza y de la movilidad social, ofrece un héroe pobre, un desheredado que consigue lo que no tiene. Este tipo de caballero obtiene sólo una herencia, que es la de su suegro.

La tercera fase comprende, aproximadamente, los siglos XVI 
y xvII, que constituyen la época del autoritarismo y del clasicismo, periodo romántico y estático, en el cual, por una parte, la baja nobleza, convertida en alta nobleza, se hace conservadora y, por otra, la clase media imita a la alta. Las obras caballerescas de esta época, en la que los reyes son fuertes, son novelas más o menos originales como el Amadís, el Palmerín, el Clarimundo y el Palmeirim. La literatura caballeresca de esta fase, que se caracteriza por la defensa de la monarquía y de la continuidad social, presenta un héroe rico, un heredero que merece lo que tiene. Este tipo de caballero recibe dos herencias: la de su padre y la de su suegro ${ }^{8}$. La tercera se inspira en la primera, siendo el eslabón que las une el Amadis, obra que encierra los ideales del feudalismo y del autoritarismo, que son, en realidad, los mismos: la corte, el linaje y la herencia. Entre ambas se encuentra la segunda fase, cuyo exponente más significativo es el Zifar, que es una obra que encarna los ideales de la burguesía: el individuo, el valor y la ganancia ${ }^{9}$.

${ }^{8}$ Pueden utilizarse las siguientes ediciones de estas obras: CyrIL MereDith-Jones (ed.), Historia Karoli Magni et Rotholandi ou Chronique du Pseudo-Turpin, Droz, Paris, 1936; LuCas De TuY, Chronicon Mundi en ANDreas SchotT (ed.), Hispaniae illustratae, IV (1608); Rodrigo XimÉnez de Rada, De rebus Hispaniae, en Hispaniae illustratae, II (1603); Ramón MenÉndez PIdal (ed.), Primera Crónica General de España que mandó componer Alfonso el Sabio y se continuaba bajo Sancho IV en 1289, Gredos, Madrid, 1955, 2 ts.; Antonio García SolaLINDE (ed.), Alfonso el Sabio, General Estoria, Junta para Ampliación de Estudios e Investigaciones Científicas, Centro de Estudios Históricos, Madrid, 1930, 3 ts.; Louis Cooper (ed.), La Gran Conquista de Ultramar, Publicaciones del Instituto Caro y Cuervo, Bogotá, 1979, 4 ts.; Cristina GonZÁlez (ed.), Libro del Caballero Zlfar, Cátedra, Madrid, 1983; Herbert L. Baird, Jr. (ed.), Análisis lingüístico y filológico de Otas de Roma, Anejos del Boletín de la Real Academia Española, XXXIII, Madrid, 1976; Ramón Miquel i Planas (ed.), Curial $e$ Güelfa, Biblioteca Catalana, Barcelona, 1932; JoAnot MAR torell y MARTí de Galba, Tirant lo Blanc, ed. Martín de Riquer, Selecta, Barcelona, 1947; Garci Rodríguez de Montalvo, Amadís de Gaula, ed. Edwin B. Place, CSIC, Madrid, 1959-1969, 4 ts.; Giuseppe di Stefano (ed.), Palmerín de Olivia, Instituto de Letteratura Spagnola e Ispano-Americana dell'Università di Pisa, Pisa, 1966; João de Barros, Crónica do Imperador Clarimundo, ed. Marques Braga, Livraria Sá da Costa, Lisboa, 1953, 3 ts.; Francisco de Morais, Crónica de Palmeirim de Inglaterra, ed. Geraldo Ulhoa Cintra, Anchieta, São Paulo, 1946, 3 ts.

${ }^{9}$ Para una introducción a estos periodos, véanse los siguientes estudios: Marc Bloch, La sociedad feudal, Uteha, México, 1958; Johan Huizinga, El otoño de la Edad Media, $9^{\mathrm{a}}$ ed., Revista de Occidente, Madrid, 1973; Alfred Von MARTin, Sociología del Renacimiento, $4^{\mathrm{a}}$ ed., FCE, México, 1968; ARnOld HAuSER, Historia social de la literatura y el arte, $4^{a}$ ed., Guadarrama, Madrid, 1971, 3 ts.; Carlos Blanco Aguinaga, Julio Rodríguez-Puértolas e Iris 
El ejemplo XXV de $E l$ conde Lucanor, protagonizado por un héroe pobre que consigue lo que no tiene, coincide plenamente con el tipo de caballero de la segunda fase, a la que, por cierto, pertenece cronológicamente esta obra. Así pues, don Juan Manuel no es original, sino que sigue la moda de su tiempo. El arquetipo del caballero de su época es un desheredado, bien sea por falta de herencia, como es el caso de Zifar, que es hijo de un hombre pobre, bien sea por falta de derecho a ella, como es el caso de Roboan, que es hijo menor de un hombre rico. Harlan Sturm señala la existencia de un parecido entre el ejemplo XXIV y el ejemplo XXV y Daniel Devoto apunta la existencia de un paralelo entre el ejemplo XXIV y el $Z_{i f a r^{10}}$. La conexión entre el ejemplo XXIV, cuyo protagonista es hijo menor de un hombre rico, y el ejemplo XXV, cuyo protagonista es hijo de un hombre pobre, entre sí y con el Zifar es evidente y reclama una éxplicación. Más productivo que postular una influencia directa del $Z i$ far sobre El conde Lucanor, lo que también se podría hacer, resulta proponer que tanto el Zifar como El conde Lucanor pertenecen a una misma corriente literaria, a la que también pertenecen Otas, Curial y Tirant ${ }^{11}$. Se trata de la literatura caballeresca burguesa, realista y dinámica de los siglos XIv y xv, tan diferente de la literatura caballeresca feudal y autoritaria, romántica y estática, de los siglos anteriores y posteriores.

A primera vista, parece un poco chocante que un miembro de la familia real castellana, como es don Juan Manuel, no defienda el modelo feudal, sino el modelo burgués del caballero. En realidad, no parece que don Juan Manuel esté a favor de la burguesía. De hecho, a juzgar por el número de ejemplos en los que condena la obtención de la riqueza mediante el comercio o el amor a la riqueza por la riqueza, parece que don Juan Manuel está en contra de la burguesía ${ }^{12}$. No puede decirse, pues, que sea un defensor de esta clase social. Sin embargo, vive en la época de la

M. ZAVAla, Historia social de la literatura española, Castalia, Madrid, 1978, 3 ts.; JAIME Vicens VIVES, Aproximación a la historia de España, Vicens Vives, Barcelona, 1978.

${ }^{10}$ HaRLan StURM, "El conde Lucanor: the search for the individual" en IAN MACPHERSON (ed.), Juan Manuel studies, Tamesis, London, p. 158; DanIEL Devoto, Introducción al estudio de don Juan Manuel y en particular de "El conde Lucanor", Castalia, Madrid, 1972, p. 412.

11 Por su cronología, no sólo el Zifar, sino también el Otas pudo haber tenido una influencia directa sobre el ejemplo XXV de El conde Lucanor.

${ }^{12}$ Los ejemplos VII (doña Truhana), XIV (el logrero), XX (el alquimis- 
burguesía y no puede dejar de estar influido por sus valores, el principal de los cuales es el del cambio social. Mi teoría es que don Juan Manuel cree en el cambio social, pero no de una clase a otra, sino dentro de cada clase. Piensa que un caballero desheredado debe llegar a ser rey si lo merece, que es lo que las novelas de caballería de este periodo predican. Como hijo menor del hijo menor del Rey Santo y como hombre que consideraba a su padre y a sí mismo más merecedores de la corona de Castilla que su tío y primo respectivamente, don Juan Manuel tiene que creer en el cambio de una situación que le resultaba difícil de aceptar. Su matrimonio con la hija del rey de Aragón es una solución caballeresca a su problema, la cual, si no le consigue un reino, sí le proporciona bastante riqueza y poder. Don Juan Manuel, es, en efecto, un Zifar o un Roboan cualquiera y no tiene nada de sorprendente que defienda este modelo caballeresco. Su colocación en el centro de la colección indica, además, que el ejemplo $\mathrm{XXV}$ constituye el corazón de su filosofía, como ya intuyó Calderón de la Barca cuando dio el título de El conde Lucanor a su versión dramática de este cuento ${ }^{13}$. No es difícil identificar al noble, valiente y culto, pero desheredado, protagonista del ejemplo XXV con la imagen que de sí mismo debía de tener el orgulloso y frustrado nieto de San Fernando. Sin embargo, don Juan Manuel hace mucho más que hablar de sí mismo en este cuento. Habla de una sociedad en cambio y toma partido, eso sí, de acuerdo con sus circunstancias personales, a favor de la nobleza y en contra de la monarquía.

Los historiadores han señalado que la Baja Edad Media se caracteriza por el constante conflicto entre la nobleza y la monarquía. Si en la época feudal y en la época autoritaria la monarquía es fuerte, en la época burguesa es débil. Entre Fernando III e Isabel I hay una serie de reyes que luchan, con más o menos éxito, contra los nobles. Joaquín Gimeno Casalduero dice que Alfonso $\mathrm{X}$ defiende a la monarquía y que don Juan Manuel defiende a la

ta), XXXVIII (el ahogado), XL (el senescal) y XLV (el ladrón) son exponentes de esta actitud.

13 Acerca de las versiones dramáticas del cuento, véanse los artículos de José Fradejas Lebrero, "Un cuento de don Juan Manuel y dos comedias del Siglo de Oro", en Antonio Doddis Miranda y Germán Sepúlveda Durán (eds.), Estudios sobre don Juan Manuel, Ed. Universitaria, Santiago de Chile, 1975, t. 1, pp. 245-272, y de Daniel Devoto, "Guatro notas sobre la materia tradicional en don Juan Manuel", $B H i, 68$ (1966), 187-216. 
nobleza, y añade que Alfonso X es ferviente partidario de la superioridad del sistema hereditario sobre el sistema electivo ${ }^{14}$. Desde luego, el modelo caballeresco del héroe rico que adopta en sus crónicas es una clara defensa de la herencia sobre la ganancia. Frente a esto, don Juan Manuel parece defender la superioridad del sistema electivo sobre el sistema hereditario, según indica el modelo caballeresco del héroe pobre que adopta en sus cuentos, que es una abierta defensa de la ganancia sobre la herencia. Es decir que el modelo caballeresco del héroe rico puede verse como una defensa de la monarquía, y el modelo caballeresco del héroe pobre como una defensa de la nobleza, la cual, durante los siglos XIV y Xv, no solamente lucha contra el rey, sino que también se transforma.

En efecto, tanto en la Península Ibérica como en el resto de Europa, en la Baja Edad Media desaparece la nobleza vieja y aparece una nobleza nueva, procedente de las ramas secundarias de las familias principales. En Castilla, este proceso se inicia cuando las minoridades de Fernando IV y Alfonso XI y se precipita a raíz de la victoria de Enrique II sobre Pedro I. Tiene sentido que, en un contexto así, prevalezca el modelo caballeresco del héroe pobre, del desheredado que consigue lo que no tiene, el cual es una defensa de los nobles frente al rey, por un lado, y de los nobles desheredados frente a los nobles herederos, por otro. Don Juan Manuel, como noble y como noble desheredado, no podía por menos que seguir este modelo caballeresco, que lo reflejaba y favorecía.

Los eruditos han comentado que don Juan Manuel era ambivalente en cuanto a la importancia del linaje y del valor. Yo no encuentro en su actitud ambivalencia alguna. Don Juan Manuel cree en el linaje y en el valor o, más exactamente, en el valor dentro del linaje. Obsérvese que el protagonista del cuento no es un simple hombre, sino todo un noble. Así, se dice que el conde de Provenza pide una lista de todos los hidalgos de la comarca:

Et envió el conde dezir a la condesa su muger et a sus parientes el consejo que el soldán le diera, et que sopiesse de quantos omnes fijos dalgo avía en todas sus comarcas, de qué maneras et de qué costumbres, et quáles eran en los sus cuerpos, et que non casassen por

14 Joaquín Gimeno Casalduero, La imagen del monarca en la Castilla del siglo XIV, Revista de Occidente, Madrid, 1972, pp. 59 y 26. 
su riqueza nin por su poder, mas quel enviassen por escrito dezir qué tales eran en sí los fijos de los reyes et de los grandes señores que la demandavan et qué tales eran los otros omnes fijos dalgo que eran en las comarcas ${ }^{15}$.

Asimismo, se dice que Saladino escoge al hijo de un ricohombre:

E desque el conde vio este escripto, mostrólo al soldán; et desque Saladín lo vio, commo quier que todos eran muy buenos, falló en todos los fijos de los reyes et de los grandes señores en cada uno algunas tachas: o de seer mal acostumbrados en comer o en vever, o en seer sañudos, o [a]partadizos, o de mal reçebimiento a las gentes, et pagarse de malas compañas, o embargados de su palabra, o alguna otra tacha de muchas que los omnes pueden aver. Et falló que un fijo de un rico omne que non era de muy grand poder, que segund lo que paresçía dél en aquel escripto, que era el meior omne et el más complido, et más sin ninguna mala tacha de que él nunca oyera fablar ${ }^{16}$.

Parece, pues, que la filosofía de don Juan Manuel respecto al juego social no es que venza el mejor hombre, sino que venza el mejor noble, es decir, él. Como dice Julio Rodríguez-Puértolas, don Juan Manuel tiene un propósito muy claro: mejorar de posición ${ }^{17}$. En persecución de este propósito, entra en el campo de la literatura caballeresca a buscar un arquetipo que le convenga y se encuentra con dos opciones: la de un pasado reciente, representada por el Amadis, y la de un futuro incipiente, representada por el Zifar. Sin vacilar, don Juan Manuel escoge la segunda, con lo que muestra que no sólo era consciente del cambio, sino que estaba a la vanguardia de éste. Aunque sienta nostalgia por el pasado que no pudo ser, don Juan Manuel tira inequívocamente hacia el futuro que todavía puede ser. Sin duda, le hubiera complacido ser rey y, de haberlo sido, hubiera escogido el modelo caballeresco del héroe rico que merece lo que tiene, pero, como era sólo un noble, escogió el modelo caballeresco del héroe pobre que consi-

15 Don Juan Manuel, El conde Lucanor, ed. José Manuel Blecua, $2^{\mathrm{a}}$ ed., Castalia, Madrid, 1971, p. 145.

${ }^{16}$ Ibid, , p. 146.

${ }^{17}$ Julio RodríGuez-PuÉRTOLAs, Literatura, historia, alienación, Labor, Barcelona, 1976, p. 50. 
gue lo que no tiene. Mejorar de posición parece ser la obsesión de su vida y de su obra y, por eso, tanto una como otra deberían estudiarse como una manifestación de los ideales caballerescos de este periodo ${ }^{18}$.

Cristina González

University of Massachusetts

${ }^{18}$ Para una introducción a esta época, véanse los siguientes estudios: LUCiana de Stefano, La sociedad estamental de la Baja Edad Media española a la luz de la literatura de la época, Universidad Central de Venezuela, Caracas, 1966; Victor R. B. Delschläger y James R. Chatham, "The structure of Spanish society in medieval literary and didactic works", $R E H 2$ (1968), 41-80; Salvador de Moxò, "De la nobleza vieja a la nobleza nueva. La transformación nobiliaria castellana en la Baja Edad Media", Cuadernos de Historia, 3 (1969), 1-210; HiLda GrassotTi, Las instituciones feudo-vasalláticas en León y Castilla, Centro Italiano di Studi Sull'Alto Medioevo, Spoleto, 1969, 2 ts.; JuLIO VALDEÓN BARUQUE, Los conflictos sociales en el reino de Castilla en los siglos XIV y XV, Siglo XXI, Madrid, 1975 y "Las tensiones sociales en Castilla en tiempos de don Juan Manuel", en Juan Manuel Studies, ed. Ian Macpherson, Tamesis, London, 1977, pp. 181-192; José Antonio Maravall, "La sociedad estamental castellana y la obra de don Juan Manuel', Cutl, 67, (1966), 751768; Celestino del ARenal, "Don Juan Manuel y su visión de la sociedad internacional del siglo XIV", CuH, 103 (1976), 90-109; NORMAN ScHAFLER, "Don Juan Manuel and the changing structure of society: a conflict", $K R Q$, 26 (1979), 181-187; ANDrés Giménez Soler, Don Juan Manuel. Biografía y estudio crítico, Real Academia Española, Zaragoza, 1932; JosÉ MARÍA CaSTro y Calvo, El arte de gobernar en las obras de Don Juan Manuel, CSIC, Barcelona, 1945; José R. Araluce Cuenca, El Libro de los Estados. Don Juan Manuel y la sociedad de su tiempo, José Porrúa Turanzas, Madrid, 1976. 